\title{
Los hijos del limo. Una aproxi- mación al discurso teórico-litera- rio de Octavio Paz en torno a la tradición y las vanguardias
}

\section{Children of the Mire. An approach to the Theore- tical-literary Discourse of Octavio Paz concerning Tradition and Vanguards}

Marco Antonio Martin Henríquez

Facultad de Humanidades y Arte, Universidad de Concepción. Concepción, Chile. mmartin@udec.cl

\section{Resumen}

En este artículo se analiza la reflexión del texto Los hijos del limo (Octavio Paz, 1972) sobre el desarrollo de las vanguardias angloamericana, francesa e hispanoamericana. Se exploran sus vínculos ideológicos y estéticos con la producción narrativa hispanoamericana, y la manera en que esta se forjó un imaginario aparte en el contexto del cambio de paradigma obrado en el pensamiento occidental, con posterioridad a la caída del metarrelato cristiano.

Palabras clave: Modernidad y narrativa, crítica literaria, desarrollo de las vanguardias, tradición europea, romanticismo, paradigma.

\section{Abstract}

This article examines the reflection of the essay Los hijos del limo (Octavio Paz, 1972) on the development of the Anglo-American, French and Latin American avant-garde. After exploring its aesthetic and ideological ties with Spanish-American narrative production, it is considered the way in which the latter forged a separate imagery in the context of the paradigm shift worked in occidental thought, following the fall of the Christian paradigm.

Keywords: Modernity and Narrative, Literary Criticism, Development of Vanguards, European Tradition, Romanticism, Paradigm. 
Como todos los niños, construí puentes imaginarios y afectivos que me unían al mundo y a los otros. Vivía en un pueblo de las afueras de la Ciudad de México, en una vieja casa ruinosa con un jardín selvático y una gran habitación llena de libros. Primeros juegos, primeros aprendizajes. El jardín se convirtió en el centro del mundo y la biblioteca en caverna encantada. Leía y jugaba con mis primos y mis compañeros de escuela. Había una higuera, templo vegetal, cuatro pinos, tres fresnos, un huele de noche, un granado, herbazales, plantas espinosas que producían rozaduras moradas. Muros de adobe. El tiempo era elástico; el espacio, giratorio. Mejor dicho: todos los tiempos, reales o imaginarios, eran ahora mismo; el espacio, a su vez, se transformaba sin cesar; allá era aquí; todo era aquí; un valle, una montaña, un país lejano, el patio de los vecinos. Los libros de estampas, particularmente los de historia,

hojeados con avidez, nos proveían de imágenes: desiertos y selvas, palacios y cabañas, guerreros y princesas, mendigos y monarcas. Naufragamos con Simbad y con Robinson, nos batimos con D’Artagnan, tomamos Valencia con el Cid.

O. Paz, La búsqueda del presente

\section{Introducción}

Hemos querido comenzar esta reflexión con unas palabras pronunciadas por el escritor mexicano en la Academia Sueca de la Lengua, pues creemos que simbolizan en parte lo que pretende este trabajo. Sabemos que la tarea que nos hemos impuesto es compleja, tan compleja como la literatura misma, pues ella-como toda creación humana- está determinada por infinitos pliegues imposibles de abarcar en un discurso. Precisamente, ahí reside lo maravilloso del universo literario: no se agota en un axioma, en una noción común (como en el campo de las ciencias), se desenvuelve en un espacio cargado de simbolismos y exégesis que no periclitan en una manifestación; vuelven una y otra vez con infinitas facetas, cada cual más compleja que la anterior.

Encontramos atingentes las palabras del escritor y poeta, porque es un lugar común hallar en Occidente personas que en algún momento de sus vidas se han sentido próximas a aquel imaginario. Excluimos de nuestro marco analítico a las otras culturas, no porque no tengan su imaginario propio, sino porque su imaginario está compuesto por otros contenidos; estos contenidos pueden tener también lugares comunes, pero sus puntos de fuga obedecen a otros arquetipos. Con esto, no negamos que el género humano no posea un tronco común, por el contrario, sabemos que esa es una verdad imposible de desconocer; lo que afirmamos es que por estar signados por diferentes visiones de mundo, no compartimos el mismo ethos. De aquí que sus modos de representar las distintas manifestaciones culturales traigan aparejadas diferencias de tonalidad. 
La teoría literaria en América Hispana ha elaborado distintas visiones teóricas, iniciándose con el ensayo Nuestra América (1891) de José Martí. Esta corriente de pensamiento ha pasado por distintas fases en su desarrollo, las que oscilan entre los enfoques americanista (cf. Henríquez Ureña 45-56), el cual ensalza la idea de rescatar la producción literaria autóctona como una manera de conquistar una identidad regional propiamente hispanoamericana; y prooccidental, que ve en la tradición literaria un fenómeno eminentemente adscrito a los modelos cristianos occidentales, pasando por distintas variantes intermedias. Así es como, en este contexto, al ya complejo panorama se han sumado otras disciplinas, las que han intervenido tratando de apropiarse del espacio literario, como una herramienta más para reafirmar sus respectivas posiciones ideológicas; no obstante, no es hasta comienzos del siglo xx cuando estas disputas comienzan a hacerse más marcadas, y ello precisamente con motivo del desarrollo y predominio de la burguesía, la que a fines del siglo XIX se instauró como el paradigma por excelencia en el mundo occidental.

Cabe preguntarse: ¿qué pasaba en el periodo inmediatamente anterior?

Pues bien, pensamos que la literatura en sus distintas expresiones estaba centrada esencialmente en Europa, ya que el continente americano aún se encontraba en pleno proceso de desarrollo político y económico, y su auge artístico en relación al continente europeo fue más bien tardío. Esto no significa que en América en tal periodo no existiera creación literaria - por el contrario, existía y en cantidad no despreciable-, sino que sus obras estaban más bien enmarcadas en relaciones de corte nacional, con algunas producciones visionarias notables que constituyen la excepción más que la regla. Octavio Paz lo comenta en estos términos:

En el siglo XVII Nueva España era una sociedad más fuerte, próspera y civilizada que Nueva Inglaterra pero era una sociedad cerrada no sólo al exterior sino al porvenir. Mientras la democracia religiosa de Nueva Inglaterra se transformó, al finalizar el siglo xviII, en la democracia política de los Estados Unidos, Nueva España, incapaz de resolver las contradicciones que llevaba en su seno estalló y, en el siglo xIX, se desmoronó (Sor Juana 67).

Es indiscutible que hay grandes puntos de convergencia entre eximios autores de la literatura americana, que van desde América del norte a Sudamérica, pero lo que queremos destacar es que no hay una visión de conjunto acerca de los grandes temas que ocupan al mundo occidental. América es un continente nuevo, que va en una fase de su desarrollo material muy por detrás del mundo de las grandes metrópolis europeas. Escribimos desarrollo material -y queremos hacer hincapié en esto-, pues no hay un ser en el mundo que sea más o menos desarrollado respecto de otro habitante del planeta en cuanto a sus capacidades; por ejemplo, Cervantes no era subdesarrollado respecto de Shakespeare porque España era materialmente menos avanzada en la revolución industrial que Inglaterra. Si a eso se le suma el haber sido colonizados fundamentalmente por dos grandes estados imperiales como España e 
Inglaterra, y en menor grado, Francia y Portugal, con una visión de mundo católica y protestante diametralmente opuesta, es plausible formarse una idea acabada de cuál es la sensibilidad imperante en los espacios geográficos hispanoamericanos.

La reflexión de nuestro trabajo se enmarca en la línea de quienes piensan que la tradición literaria hispanoamericana es tributaria de la cultura occidental. Pensamos que Octavio Paz es uno de ellos. Por lo mismo, hemos elegido una de las obras más representativas de su pensamiento, como es Los hijos del limo, no sin antes dejar en claro que en ningún caso aseveramos que en otros títulos del autor no se transite por las mismas ideas, sino que, a nuestro entender, aquella es la que mejor condensa la perspectiva que queremos abordar.

\section{I}

Antes de comenzar nuestra disquisición respecto de la tradición del quiebre o la ruptura, como afirma Octavio Paz, se hace imprescindible hacer una sucinta digresión anteponiendo un proemio. La tradición occidental no ha aparecido en la historia sin antes haber permanecido en varios estadios. En el comienzo, la humanidad se encuentra en una faceta que muy bien describe Mircea Eliade: "El Mundo se presenta de tal manera que, al contemplarlo, el hombre religioso descubre los múltiples modos de lo sagrado y, por consiguiente, del Ser. Ante todo, el Mundo existe, está ahí, tiene una estructura: no es un Caos, sino un Cosmos; por tanto, se impone como una creación, como una obra de los dioses" (71). De este punto se pasa al racionalismo griego, que si bien estaba teñido por ideas heredadas de su pasado mítico más inmediato, es el primer esfuerzo sistematizador del conocimiento en el mundo occidental. Allí se instalan dos grandes tendencias: una corriente que va por la línea de Platón y otra que circula por la corriente de pensamiento que pasa por Aristóteles. En medio de ambas se situará el cristianismo, que es una variante del judaísmo, religión monoteísta por excelencia. En las dos primeras concepciones, hay un concepto del tiempo radicalmente opuesto al tiempo lineal cristiano, que establecía un momento de la creación y un tiempo del fin de esta. Este hecho es de enorme trascendencia, pues se legitima una visión que parte del supuesto de que hay un principio que debe desembocar necesariamente en un telos, en el cual se termina la historia. Este estado de cosas permanece casi inalterado hasta el final de la Edad Media y el principio de la modernidad, tiempo en el que opera una revolución que trastrocará todos los modelos hasta entonces vigentes. Cabe preguntarnos: ¿qué pasó con la tradición? Octavio Paz señala a este respecto:

Se entiende por tradición la transmisión de una generación a otra de noticias, leyendas, historias, creencias, costumbres, formas literarias y artísticas, ideas, estilos; por tanto, cualquier interrupción en la transmisión equivale a quebrantar la tradición. Si la ruptura es destrucción del vínculo que nos une al pasado, 
negación de la continuidad entre una generación y otra, ¿puede llamarse tradición a aquello que rompe el vínculo e interrumpe la continuidad?” (Los hijos del limo 17).

Efectivamente, la modernidad no rompe los lazos definitivamente con la tradición anterior a ella, sino que hace uso de esta y al mismo tiempo subvierte su escala de valores, se sirve de ella y genera su propio universo. Lo que singulariza a la modernidad respecto de todas las demás épocas en la historia de Occidente es precisamente su ruptura con el hilo conductor que venía desde los tiempos anteriores, especialmente con el cristianismo. La modernidad vista así es un fenómeno distinto, ahí radica todo su poder de seducción. Ya nos lo dice Octavio Paz: "Lo nuevo nos seduce no por nuevo sino por distinto; y lo distinto es la negación, el cuchillo que parte en dos al tiempo: antes y ahora" (20-1).

No obstante, a pesar de no sentirse tributaria de ningún otro periodo, no escatima esfuerzos en ir a beber del manantial del mundo clásico grecolatino e inclusive más atrás. Leemos:

Lo viejo de milenios también puede acceder a la modernidad: basta con que se presente como una negación de la tradición y que nos proponga otra. Ungido por los mismos poderes polémicos que lo nuevo, lo antiquísimo no es un pasado: es un comienzo. La pasión contradictoria lo resucita, lo anima y lo convierte en nuestro contemporáneo. En el arte y en la literatura de la época moderna hay una persistente corriente arcaizante que va de la poesía popular germánica de Herder a la poesía china desenterrada por Pound, y del Oriente de Delacroix al arte de Oceanía amado por Bretón. Todos esos objetos, trátese de pinturas y esculturas o de poemas, tienen en común lo siguiente: cualquiera que sea la civilización a que pertenezcan, su aparición en nuestro horizonte estético significó una ruptura, un cambio (21).

La modernidad es una revolución total, su pretensión no conoce límites; el cortapisas está dado sólo por el sujeto, el mismo que ve en permanente transformación y cambio. Si los antiguos se imaginaban los acontecimientos como una constante repetición de ciclos, para el hombre moderno cada momento es único e irrepetible. De este modo, la crítica moderna reafirma su mirada en la otredad como baluarte de su impronta. Como toda revolución totalizadora, el tiempo moderno solo puede situarse allende la contingencia, Octavio Paz refiere:

El remedio contra el cambio y la extinción es la recurrencia: el pasado es un tiempo que reaparece y que nos espera al fin de cada ciclo. El pasado es una edad venidera. Así, el futuro nos ofrece una doble imagen: es el fin de los tiempos y es su recomienzo, es la degradación del pasado arquetípico y es su resurrección. El fin del ciclo es la restauración del pasado original -y el comienzo de la inevitable degradación. La diferencia entre esta concepción y las de los cristianos y los 
modernos es notable: para los cristianos el tiempo perfecto es la eternidad: una abolición del tiempo, una anulación de la historia; para los modernos la perfección no puede estar en otra parte, si está en alguna, que en el futuro (29-30).

De esta manera, la tragedia cósmica pasa de lo impersonal en el tiempo mítico al drama personal del cristianismo, el que busca la salvación del sujeto a fuerza de que se someta a los designios decretados por el creador. No será hasta los comienzos de la modernidad que se posicionará el cambio como eje central de su ideario. Esto en principio no es nuevo, ya que en Grecia los grandes filósofos habían indagado en la misma querella, solo que con otros actores; del ser inmóvil de Parménides se pasó a las esencias puras de Platón, para llegar a la filosofía de un aristócrata misántropo como Heráclito de Éfeso, que postulaba que todo está sujeto a la inevitabilidad del cambio.

\section{II}

La insurrección moderna, recogiendo en parte este legado, también adoptará el cambio como una de sus ideas axiales. Este principia en dos dualismos, Dios y ser, revelación y razón, ambas posturas irreconciliables. El Dios del evangelio no tolera la insumisión, la razón, por el contrario, siempre se ve a sí misma escindida y, en tanto tal, otra. Cuando se realiza una introspección, en su imagen especular se aprecia siempre como diferencia, puro devenir y alteridad. De este modo, su manera de ser se perpetúa.

La idea de progreso es connatural al discurso moderno, por eso el hombre instalado en la modernidad vive inmerso en un mar de especulaciones que se inventa y recrea en un perpetuo devenir. De ahí su afición por la historia, pues esta le provee de un suceder en constante transformación a través de escalas progresivas, y un sitio en el que encuentra un metarrelato tan fuerte como aquel al que pretende suplantar. Tal es su anhelo metafísico, uno que no parte de la fe, sino de su anverso, su doble, pero laico. Para ello se aferra a una categoría temporal como es el futuro, al que le otorga un rango ontológico tan inclusivo como la divinidad. Octavio Paz nos recuerda: El gran cambio revolucionario, la gran conversión, fue la del futuro. En la sociedad cristiana el porvenir estaba condenado a muerte: el triunfo del eterno presente, al otro día del Juicio Final, era asimismo el fin del futuro. La modernidad invierte los términos: si el hombre es historia y sólo en la historia se realiza; si la historia es tiempo lanzado hacia el futuro y el futuro es el lugar de elección de la perfección; si la perfección es relativa con relación al porvenir y absoluta frente al pasado, pues entonces el futuro se convierte en el centro de la tríada temporal: es el imán del presente y la piedra de toque del pasado. Semejante al presente fijo del cristianismo, nuestro futuro es eterno. Como él, es impermeable a las vicisitudes del ahora e invulnerable a los horrores del ayer. Aunque nuestro futuro es una proyección de la historia, está por definición más allá de 
la historia, lejos de sus tempestades, lejos del cambio y de la sucesión. Si no es la eternidad cristiana, se parece a ella en ser aquello que está del otro lado del tiempo: nuestro futuro es simultáneamente la proyección del tiempo sucesivo y su negación. El hombre moderno se ve lanzado hacia el futuro con la misma violencia que el cristiano se veía lanzado hacia el cielo o al infierno (54-5).

Si se vierten estos conceptos al campo literario, esto produce un radical cambio en la sensibilidad: la que había empezado con los prerrománticos toma renovados e intensos bríos y va a posicionarse con gran fuerza en el romanticismo alemán. Edificar un poema equivale a crear un mundo aparte, todo se critica: el lenguaje, la literatura, la prosa. Como lo indica Octavio Paz:

La sensibilidad de los prerrománticos no tardará en convertirse en la pasión de los románticos. La primera es un acuerdo con el mundo natural, la segunda es la transgresión del orden social. Ambas son naturaleza, pero naturaleza humanizada: cuerpo. Aunque las pasiones corporales ocupan un lugar central en la gran literatura libertina del siglo xviII, sólo hasta los prerrománticos y los románticos el cuerpo comienza a hablar. Y el lenguaje que habla es el lenguaje de los sueños, los símbolos y las metáforas, en una extraña alianza de lo sagrado con lo profano y de lo sublime con lo obsceno (58).

El anuncio moderno que difundía un mundo donde el hombre había asumido un rol autopoiético, que se había abandonado a la idea de progreso infinito de manos de la suprema razón, será enjuiciado por los románticos, pues si bien ellos celebran el desplazamiento de Dios, no son menos caústicos a la hora de criticar la razón. Los vanguardismos modernos no han desplazado al cristianismo para caer en su reverso seglar, sino para edificar un nuevo orden, en que el hombre y la creación poética son el centro y fin último de todas las teleologías posibles. Citamos:

La crítica de la religión emprendida por la filosofía del siglo xviı quebrantó al cristianismo como fundamento de la sociedad. La disgregación de la eternidad en tiempo histórico hizo posible que la poesía, en una suerte de regreso a sí misma y por la misma naturaleza de la función poética, indistinguible de la función mítica, se concibiese como el verdadero fundamento de la sociedad. La poesía fue la verdadera religión y el verdadero saber. Las biblias, los evangelios y los coranes habían sido denunciados por los filósofos como compendios de patrañas y fantasías; sin embargo, todos reconocían, incluso los materialistas, que esos cuentos poseían una verdad poética (Paz 81).

Si se revisan las proposiciones teóricas de algunos de los representantes más destacados de la poesía moderna, nos percatamos inmediatamente de que la lírica anhela un espacio gravitante; por ejemplo, William Blake ve la filosofía como supersticiosa, a la racionalidad como idólatra y se muestra pesimista respecto del nuevo culto a la 
nueva religión del progreso. Un ejemplo de ello es que Blake signa a los instrumentos de la sociedad del capital, como usinas, fraguas, maquinarias que reproducen bienes en serie, como artefactos malignos que oprimen al hombre en lugar de liberarlo. Octavio Paz nos recuerda:

Los poetas románticos fueron los primeros en afirmar, lo mismo ante la religión oficial que ante la filosofía, la anterioridad histórica y espiritual de la poesía. Para ellos la palabra poética es la palabra de fundación. En esta afirmación temeraria está la raíz de la heterodoxia de la poesía moderna tanto frente a las religiones como ante las ideologías (82-3).

Otro tanto ocurre con otros poetas, como Goethe en Doctor Fausto, Mallarmé en el Igitur o Baudelaire en Las flores del mal -por mencionar algunos-. Todos de alguna forma retornan a saberes hermético-paganos que simultáneamente alternan con un retorno a lo clásico griego, cuando el mundo estaba aún involucrado con creencias místico-mágicas; hecho que no es una mera casualidad, sino que atiende justamente a ese sentimiento de rebeldía, a causa de la censura a este periodo anterior al cristianismo, que durante siglos la religión oficial se había ocupado de hacer digna de la más perseverante clausura. La retórica del escritor mexicano es contundente al respecto:

Esas fronteras fueron también y sobre todo lingüísticas: el romanticismo nació y alcanzó su plenitud en las naciones que no hablan las lenguas de Roma. Ruptura de la tradición que hasta entonces había sido central en Occidente y aparición de otras tradiciones: la poesía popular y tradicional de Alemania e Inglaterra, el arte gótico, las mitologías celtas y germánicas e incluso, frente a la imagen que la tradición latina nos había dado de Grecia, el descubrimiento (o la invención) de otra Grecia -la Grecia de Herder y de Hölderlin, que será más tarde la de Nietzsche y la nuestra. El guía de Dante en el infierno es Virgilio, el de Fausto es Mefistófeles. ¡Los clásicos! -dice Blake refiriéndose a Homero y Virgilio-, fueron los clásicos, no los godos o los monjes, los que asolaron a Europa con guerras (96).

Cómo no coincidir con el Nobel mexicano cuando Gerard de Nerval en Las Quimeras declama:

¡Hombre, libre pensador! - Te crees tú el único pensante

en este mundo donde la vida estalla en todas las cosas

Las fuerzas que tú tienes tu libertad dispone.

Pero de todos tus consejos el universo está ausente.

Respeta en la bestia a un espíritu activo...

cada flor es un alma a la naturaleza abierta;

un misterio de amor en el metal reposa:

¡"Todo es sensible” y todo en tu ser es poderoso!

Teme en el muro ciego de una mirada que te espía: 
a la materia misma un verbo está agregado...

¡No la hagas servir en algún uso impío!

A menudo en el ser oscuro, habita un dios escondido;

y como un ojo naciendo cubierto por sus párpados,

¡Un puro espíritu crece bajo la corteza de las piedras! (7).

O cuando en un sentido similar se expresa Baudelaire en Las flores del mal, en el poema Lesbos, incluido en las poesías condenadas, que recita:

Madre de juegos latinos y voluptuosidades griegas,
oh Lesbos, con besos lánguidos o alegres,
como el sol ardientes, como la sandía frescos,
que adorno son de noches y días de gloria,
madre de juegos latinos y voluptuosidades griegas (182).

Subversión e inversión del orden establecido, los poetas a través de la creación literaria buscan un lugar en el que puedan permanecer a resguardo tanto del paradigma cristiano como de la tradición positivista moderna; ni una ni otro les satisface, ambos les saben igualmente opresores, por eso no quieren renunciar a su prerrogativa de ser sujetos excepcionales que necesitan legitimarse como opción a los grandes sistemas. Al mundo moderno con su linealidad agustiniana, su historicidad y cambio permanente, el poeta interpondrá el arbitraje de la metáfora. De este modo, conjura la existencia de la alteridad instalada por el empirismo y la ciencia moderna, que ha revocado la unidad del cosmos, ese libre albedrío sustentado en la libertad y el derecho a la rebelión.

Si el cambio de paradigma moderno produjo el romanticismo alemán y el simbolismo francés como los dos grandes ejes temáticos literarios occidentales, no es menos cierto que ambas corrientes perderán su empuje inicial o se degradarán en otras manifestaciones en la segunda mitad del siglo del xx; no con la fuerza ni la originalidad de sus primeros periodos, pero sí obrando como un referente que introduce configuraciones que se mostrarán bajo otras expresiones, derivando hacia disciplinas que no estaban en su inmediata esfera de influencia. Dicho de otro modo, cobran relevancia otras áreas del saber que, por ser más especializadas, ocuparán el espacio dejado por las vanguardias y llevarán sus planteamientos a planos nuevos e insospechados, como el psicoanálisis, la lingüística y la antropología, solo por mencionar algunas más cercanas al campo de significancia vanguardista.

En lo que respecta al mundo de habla hispana, por tener fuertes influencias de la península, prácticamente casi no experimentó la modernidad. La sociedad española, fuertemente controlada por la iglesia, no conoció los efectos de la Ilustración ni de la Revolución Francesa, por lo que era básicamente un mundo aparte del resto de Europa. Su inveterado dogmatismo y enclaustramiento religioso impidió que los nuevos aires modernos permearan su cuerpo social. No obstante, un evento vino a modificar la 
situación: el descubrimiento de América, espacio geográfico nuevo que se convirtió en escenario de la confrontación entre los dos grandes modelos: el de América del Norte, conquistado por ingleses y franceses, donde se consolidó el ideario de la reforma así como la expansión ideológica de los valores e ideas modernas de corte empirista, y el español, que venía lastrado por un conservadurismo, herencia del medioevo. Hasta tal punto en la América Hispana se puede constatar esta diferencia ideológica, que hemos recurrido a un artículo de Mario Rodríguez para refrendar nuestra postura, quien lo describe maravillosamente refiriéndose a la novela latinoamericana:

Un nacimiento espurio el de la novela, en cuanto el relato de las mundanidades más pequeñas la llevó a incursionar en los secretos mejor guardados, en los deseos más desvergonzados, en acciones que hasta ese entonces sólo se verbalizaban en el confesionario, donde una vez dichos se evapor aban en el aire. Obligada a traspasar los límites, a registrar en un archivo lo que había permanecido en el secreto del confesionario, a descubrir en forma insidiosa o brutal los pensamientos más privados, la novela desplazó las reglas y los códigos para constituirse en un discurso de la infamia, un discurso que no se refería a hechos y hombres famosos, sino a lo más intolerable, lo peor, lo más oculto, lo más alejado de la fama (13-4).

Contemplado desde otra perspectiva, si en Europa el cisma protestante obró como un vehículo que expandió el capitalismo, el continente recién incorporado al patrimonio occidental también sirvió como un espacio territorial para experimentar el nuevo modelo. No ocurrió lo mismo en América, colonizada por la España católica y Portugal, en la que era casi inexistente la crítica al igual que en la península, en la que durante siglos el ethos ciudadano permaneció casi inalterado. Como era de esperarse, este quietismo fue traspasado a todos los países fundados por la Corona, con la salvedad de que en el nuevo mundo las ideas conservadoras fueron aun mucho más severas que en la misma metrópolis. Como lo indica Octavio Paz:

El romanticismo hispanoamericano fue aún más pobre que el español: reflejo de un reflejo. No obstante, hay una circunstancia histórica que, aunque no inmediatamente, afectó a la poesía hispanoamericana y la hizo cambiar de rumbo. Me refiero a la Revolución de Independencia. (En realidad debería emplear el plural, pues fueron varias y no todas tuvieron el mismo sentido, pero, para no complicar demasiado la exposición, hablaré de ellas como si hubiesen sido un movimiento unitario.) Nuestra Revolución de Independencia fue la revolución que no tuvieron los españoles -la revolución que intentaron realizar varias veces en el siglo xix y que fracasó una y otra vez. La nuestra fue un movimiento inspirado en los dos grandes arquetipos políticos de la modernidad: la Revolución francesa y la Revolución de los Estados Unidos. Incluso puede decirse que en esa época hubo tres grandes revoluciones con ideologías análogas: la de los franceses, la de los norteamericanos y la de los hispanoamericanos (Los hijos del limo 124). 
Tal estado de cosas solo pudo ser modificado bien avanzada la modernidad, gracias a las ideas nuevas que llegaron a América de la mano de los nuevos próceres que lideraban el movimiento emancipador, tanto en Estados Unidos como en el resto del continente americano. Este ideario transformó lentamente las viejas estructuras sociales impuestas por la Corona. A este escenario se agrega la inmigración, la que se hizo mucho más frecuente, con el consiguiente cosmopolitismo e intercambio de ideas que trajo aparejado. Ángel Rama nos refiere en La ciudad letrada:

La constitución de las literaturas nacionales que se cumple a fines del xix es un triunfo de la ciudad letrada, la cual por primera vez en su larga historia, comienza a dominar a su contorno. Absorbe múltiples aportes rurales insertándolos en su proyecto y articulándolos con otros para componer un discurso autónomo que explica la formación de la nacionalidad y establece admirativamente sus valores (74).

Ciudad letrada, ciudad emergente, ciudad que se instala en las antípodas de la urbe colonial española, pero que, no obstante, en ningún momento puede abstraerse del reciente acontecimiento de las ideas modernas, fruto del marco ideológico de Occidente. Roberto Hozven nos recuerda el modernismo en América, el que describe en estos términos:

La primera operación poética que resalta se refiere al acto por el cual los modernistas se apropian de la historia ajena como si fuera propia, lo que trae aparejado, por inversión recíproca, experimentar la propia subjetividad como si fuera la proyección de una otredad. Esta operación intersubjetiva mutante, y no ya sólo subjetiva, enlaza el signo histórico de vivir bajo la dependencia de lo que se aborrece, lo que nos hace "oscilar entre la rebelión y la abyección", con la necesidad de traducir y configurar el nuevo espacio cultural como un espacio de operaciones hecho de invenciones y de sorpresas. Por ejemplo, manifestar su desdén, como Poe, pero con los mismos materiales de lo desdeñado o afirmar su vitalismo, como Whitman, pero con aquello mismo en que se enajenan (119).

Al igual que sus pares románticos y simbolistas europeos, los modernistas hispanoamericanos tienen una posición ambivalente, las diferencias son de matices y fuentes. No será hasta después de la segunda mitad del siglo xix que la producción literaria latinoamericana va a insertarse en planos de igualdad con la vieja Europa. Rama escribe:

Debe observarse que la modernización se extiende impetuosamente por un periodo de casi 40 años, partiendo de los primeros tanteos al establecerse el orden liberal positivo hacia 1870, desarrollándose bajo la cerrada oposición que también ilustrara Fray Candil, conquistando progresivamente su nuevo público para encontrar en el mismo centenario de la independencia, ya alcanzada su oficialización, la recusación de los nuevos sectores sociales que promoverán el 
regionalismo y el vanguardismo (o modernismo en el Brasil): En la década de los años diez ya están produciendo, coetáneamente, Rómulo Gallegos y Vicente Huidobro (La crítica de la cultura 89).

Haciendo una cronología del vanguardismo en América, se puede establecer la siguiente disposición:

La vanguardia latinoamericana desarrolla su acción y propuesta en dos momentos igualmente importantes, uno que va de 1915 a 1929 y otro que va de 1930 a 1940. Estos dos momentos en que se desarrolla el proceso de la vanguardia se enmarcan históricamente por los hitos que corresponden a la Primera Guerra Mundial (1914-1918), la crisis económica mundial conocida como el crack del '29 (1929-1930) y el inicio de la Segunda Guerra Mundial (De la Fuente 6).

En este lapso de tiempo hacen su puesta en escena algunos giros que son representativos de una identidad vanguardista americana. Bien lo menciona Octavio Paz:

Pero la alternativa extrema fue la aparición de un nuevo cosmopolitismo, ya no emparentado con el simbolismo, sino con la vanguardia francesa de Apollinaire y Reverdy. Como en 1885, el iniciador fue un hispanoamericano: a fines de 1916 el joven poeta chileno Vicente Huidobro llega a París y poco después, en 1918 en Madrid, publica Ecuatorial Poemas árticos (Los hijos del limo 200-1).

A él se le suma Cesar Vallejo con su obra Los Heraldos Negros de 1918. Como alternativa al creacionismo de Vicente Huidobro, harán su puesta en escena el dadaísmo, el surrealismo, el futurismo, el realismo socialista, el cubismo, entre otras tendencias. De hecho, Octavio Paz es más bien de la opinión de que en Hispanoamérica casi no existió el surrealismo, salvo una excepción a la regla, como fue el grupo chileno "La Mandrágora”, con Braulio Arenas, Enrique Gómez Correa, Gonzalo Rojas y Jorge Cáceres. En un artículo publicado recientemente, un articulista dice de la vanguardia latinoamericana:

La estabilidad del conjunto de sus expresiones artísticas y literarias se sostiene en los polos de una dialéctica: cosmopolita o nacionalista, colectivo o individual, racional o irracional; cualquiera sea el modo en que se resuelva, opera desde fuera la articulación con las utopías sociales americanas (la revolución mexicana por ejemplo), en un momento en que se constituyen los movimientos reivindicativos, impulsados por el afán de los cambios en las condiciones de vida y la superación de las crisis de los años 30 y la situación de posguerras, que afectó de modo global las distintas sociedades (Ferrada 124).

Más allá de cualquier análisis minucioso, lo que sí se puede decir es que las vanguardias, tanto en el viejo como en el nuevo continente, comparten ideas. Muchas de ellas estuvieron comprometidas con corrientes políticas como el marxismo, el fascismo 
o el anarquismo, porque, a pesar de sus diferencias, hubo al menos algo en lo que estuvieron de acuerdo: su arrebato transgresor de un modelo antropológico que había conducido a dos guerras mundiales. En lo que difirieron fue en sus respectivos enfoques: la vanguardia hispanoamericana era más decimonónica, pues sus planteamientos políticos, más allá de toda crítica, seguían buscando la transformación social. Por eso rescataron las expresiones culturales del continente africano, al que miraban con especial deferencia por ser el símbolo de la exclusión y el paradigma más brutal del expolio moderno; así como todas las manifestaciones autóctonas americanas, que consideraban con particular detenimiento por ser también sectores excluidos del universo de las clases dominantes europeizantes. Citamos:

Basta observar la fecundidad de algunos de esos itinerarios, cuando son vividos por intelectuales como Vallejo, Mario de Andrade, Oswald de Andrade, Borges, Carpentier o Mariátegui; y basta detenerse en la forja de ciertos conceptos polémicos (como "nacionalismo pragmático" y "nacionalismo crítico" de Mário; "antropofagia" de Oswald; "nación incompleta", "esbozo de Nación" de Mariátegui; o, en otra perspectiva "realismo mágico" de Asturias y "real maravilloso" de Carpentier) para reconocer en esas invenciones del pensamiento la fantasía y el trabajo de una razón interna y la expresión de un hambre de verdad (Schwartz 22).

Tras la segunda mitad del siglo xx, muchos de estos movimientos declinaron o simplemente se diluyeron. El desgaste y agotamiento de los metarrelatos condujo a un desencanto generalizado. La sociedad posindustrial va a ceder el paso a otro tipo de narrativa, más centrada en el individuo, sin grandes apetitos universales.

Como conclusión, e independientemente de que otras posturas teóricas acerca de la obra literaria en el continente americano sostengan sus propios planteamientos, es incontrovertible que somos tributarios de una tradición que tiene su principio en otra práctica más antigua y que viene de Europa; por lo mismo, compartimos plenamente con Jorge Luis Borges lo que afirmó acerca de la producción literaria en América.

Creo que nuestra tradición es toda la cultura occidental, y creo también que tenemos derecho a esa tradición, mayor que el que pueden tener los habitantes de una u otra nación occidental. Recuerdo aquí un ensayo de Thorstein Veblen, sociólogo norteamericano, sobre la preeminencia de los judíos en la cultura occidental. Se pregunta si esta preeminencia permite conjeturar una superioridad innata de los judíos, y contesta que no; dice que sobresalen en la cultura occidental, porque actúan dentro de esa cultura y al mismo tiempo no se sienten atados a ella por una devoción especial; "por eso -dice- a un judío siempre le será más fácil que a un occidental no judío innovar en la cultura occidental"; y lo mismo podemos decir de los irlandeses en la cultura de Inglaterra (160-1). 


\section{Referencias}

Baudelaire, Charles. Las flores del mal. Madrid: Visor, 1982. Impreso.

Borges, Jorge Luis. Discusión. Madrid: Alianza, 1997. Impreso.

De la Fuente, Alberto. "Vanguardias literarias: ¿una estética que nos sigue interpelando?”. Literatura y Lingüística 16 (2005): 31-50. Impreso.

Eliade, Mircea. Lo sagrado y lo profano. $4^{\mathrm{a}} \mathrm{ed}$. Barcelona: Guadarrama/Punto Omega, 1981. Impreso.

Ferrada Alarcón, Ricardo. "La vanguardia literaria: una instancia formativa del discurso crítico latinoamericano". Literatura y Lingüística 18 (2007): 121-134. Impreso.

Henríquez Ureña, Pedro. La utopía de América. Caracas: Biblioteca Ayacucho, 1989. Impreso.

Hozven, Roberto. Octavio Paz: viajero del presente. México: El Colegio Nacional, 1994. Impreso.

Nerval, Gerard de. Las Quimeras. Valparaíso: Ediciones Universitarias de Valparaíso, 1976. Impreso.

Paz, Octavio. Sor Juana Inés de la Cruz o las trampas de le fe. Barcelona: Seix Barral, 1982. Impreso.

---. "La búsqueda del presente". Brindis en el banquete ofrecido por el Ayuntamiento de Estocolmo. Nobelprize.org. The Official Web Site of the Nobel Prize. 1990. $<$ http://www.nobelprize.org/nobel_prizes/literature/laureates/1990/paz-lectures.html>. Web.

---. Los hijos del limo. Barcelona: Seix Barral, 1998. Impreso.

Rama, Ángel. La crítica de la cultura en América Latina. Caracas: Biblioteca Ayacucho, 1985. Impreso.

---. La ciudad letrada. Montevideo: Arca, 1998. Impreso.

Rodríguez Fernández, Mario. "Novela y poder: El panóptico. La ciudad apestada. El lugar de la confesión”. Atenea 490 (2004): 11-32. Impreso.

Schwartz, Jorge. Las vanguardias latinoamericanas. Textos programáticos y críticos. Madrid: Cátedra, 1991. Impreso.

Recibido: 15 septiembre 2014 Aceptado: 17 agosto 2015 